\title{
Microscopic Characteristics Of Scalp Hair Subjected To Cultural Styling Methods In Ghanaian African Females
}

This article was published in the following Dove Press journal: Clinical, Cosmetic and Investigational Dermatology

\author{
Esther Adjoa Essel (D) \\ John Ahenkorah (iD) \\ Richard Michael Blay (DD \\ Saviour Kweku Adjenti \\ Kevin Kofi Adutwum- \\ Ofosu (iD) \\ Bismarck Afedo Hottor \\ Frederick Kwaku Addai (D) \\ Department of Anatomy, School of \\ Biomedical \& Allied Sciences, College of \\ Health Sciences, University of Ghana, \\ Accra, Ghana
}

Correspondence: Frederick Kwaku Addai Department of Anatomy, School of Biomedical \& Allied Sciences, College of Health Sciences, University of Ghana, P. O. Box KB 143, Korle-Bu Campus, Accra, Ghana

Tel +233244643209

Email addaifrederick88@gmail.com
Purpose: To provide data for forensic use and provoke ideas to preserve shaft integrity, we studied microstructural alterations of female scalp hair subjected to Ghanaian cultural styling methods. Hence, topographical features of female hairs styled by braiding/weaving, and chemical relaxation sampled from five different scalp regions were assessed and compared with natural (Afro) hair.

Subjects and methods: Ninety-six indigenous Ghanaian females volunteered 480 hairs, which were analyzed by light microscopy. Hairs were plucked using a pair of cosmetologist's tweezers from frontal, left temporal, right temporal, vertex, and occipital regions of the scalp. Hairs were categorized by their grooming styles as Afro (natural-unstyled), natural-styled (weaved/braided), and chemically relaxed. These were studied according to shaft/medulla dimensions and conventional cuticular scale features, and comparisons were made between styling procedures and scalp regions. Results: Chemically styled hair had the widest shaft diameter, but the lowest incidence of continuous medullation. Medullary diameter and index increased from chemically relaxed, natural-styled, to Afro hair. A positive but modest correlation between shaft and medullary diameters existed for Afro $(\mathrm{r}=0.320, \mathrm{p}=0.011)$ and natural-styled hairs $(\mathrm{r}=0.235, \mathrm{p}=$ $0.022)$ but not chemically relaxed hair $(r=0.122, p=0.2)$. Scale margins were predominantly smooth in Afro hair, crenate in natural-styled hair, and rippled in chemically relaxed hair. With respect to scalp regions, hair shaft diameter was widest in vertex hair and smallest in right temporal hair in all styling methods.

Conclusion: Medulla was thickest in Afro hair, which also exhibited a correlation with shaft diameter in conformity with the published data. Chemically relaxed hairs did not exhibit these characteristics, which affirm altered morphology. Research on how chemicals affect these changes should help find antidote. The dimensional variations of hairs from different scalp regions are instructive for both cosmetic and forensic examination of hairs.

Keywords: skin appendage, integument, strand grooming, fiber scales, Afro hair

\section{Introduction}

Black African hairs have been described as forming a mat of tightly interwoven hair shafts in situ, and having a tight, coiled, and springlike structure when collected by combing. ${ }^{1}$ It is known that hair care practices and hair fiber morphology vary among African-American women, and both are proffered to contribute to clinically observed variation in hair fragility and growth. ${ }^{2}$ An excellent review ${ }^{3}$ has recently described traditional and widespread hair care procedures that transiently or permanently affect hair fiber features. There is a general acknowledgment that in females 
scalp, hair forms part of physical identity leading to increasing artificial modifications for esthetic purposes. ${ }^{4}$ Historically and culturally, identity for Black females, in particular, is inextricably linked with their relationship to and presentation of their hair; therefore, many methods have evolved over centuries to groom the scalp hair of the African woman. ${ }^{5}$

Hair grooming among Ghanaian females may be classified according to Roseborough and McMichael. ${ }^{6}$ The latter authors assert that hairstyles such as braiding, weaving, and heat-styling may overlap between the natural versus chemically relaxed hairs as shown in Figure 1. Chemical treatment of natural Negroid hair breaks disulfide bonds that give hair its strength, thereby weakening it and affecting the gross appearance. ${ }^{7}$ However, it is apparent that there is a paucity of information on the nature/ manner of structural modification exerted on African hair shaft by chemical treatment.

Given the dependence of the gross appearance of hair on the integrity of its microstructure, ${ }^{8}$ the latter is expected to be altered by the artificial modifications involved in styling. There is relatively sparse information on how common hairstyling techniques affect the microscopic profile of West African Negroid hair. It is postulated that providing structural correlates to alteration resulting from chemical treatment may offer ideas for amelioration and/or better preservation of such hair. The present study therefore assessed the microscopic morphological characteristics of indigenous Ghanaian female scalp hair taken from women adopting three culturally elective grooming techniques. The findings of this study are also useful in cosmetology, dermatology, and forensic investigations.

\section{Materials And Methods}

Permission for this study was obtained from the Ethical and Protocol Review Committee of College of Health Sciences, University of Ghana, Korle-Bu Campus (Permission ID No. MS-Et/M.7-P4.4/2014-2015). Convenient (and purposive) sampling was adopted to select participants who completed a questionnaire designed to establish that three generations of either parent were indigenous Ghanaians. Females were aged between 14 and 55 years and had volitionally adopted either natural or chemically relaxed hair-grooming method. Informed consent was obtained from each participant in written form and for participants aged below 18 years, consent forms were completed and signed by their parents. The natural hair was either Afro (unstyled) or styled (braids, twists, corn-row or weaved) and was devoid of chemical treatment. The chemically relaxed hair was treated and styled. Equal numbers of participants (32) were recruited whose hairstyle could be classified as Afro, or natural-styled, or chemically relaxed. A pair of cosmetologist's tweezers was used to pluck five scalp hair strands from each of five different scalp regions; namely frontal, left, and right temporal, vertex, and occipital. Thus, each participant volunteered 25 hair strands kept in five labelled envelopes corresponding with the five regions of the scalp. As previously described, the hairs were cleaned using 5\% alcohol $(5 \% \mathrm{v} / \mathrm{v})$ for $35 \mathrm{mins}$, blotted clean and allowed to dry at room temperature $\left(20^{\circ} \mathrm{C}\right) .9,10$

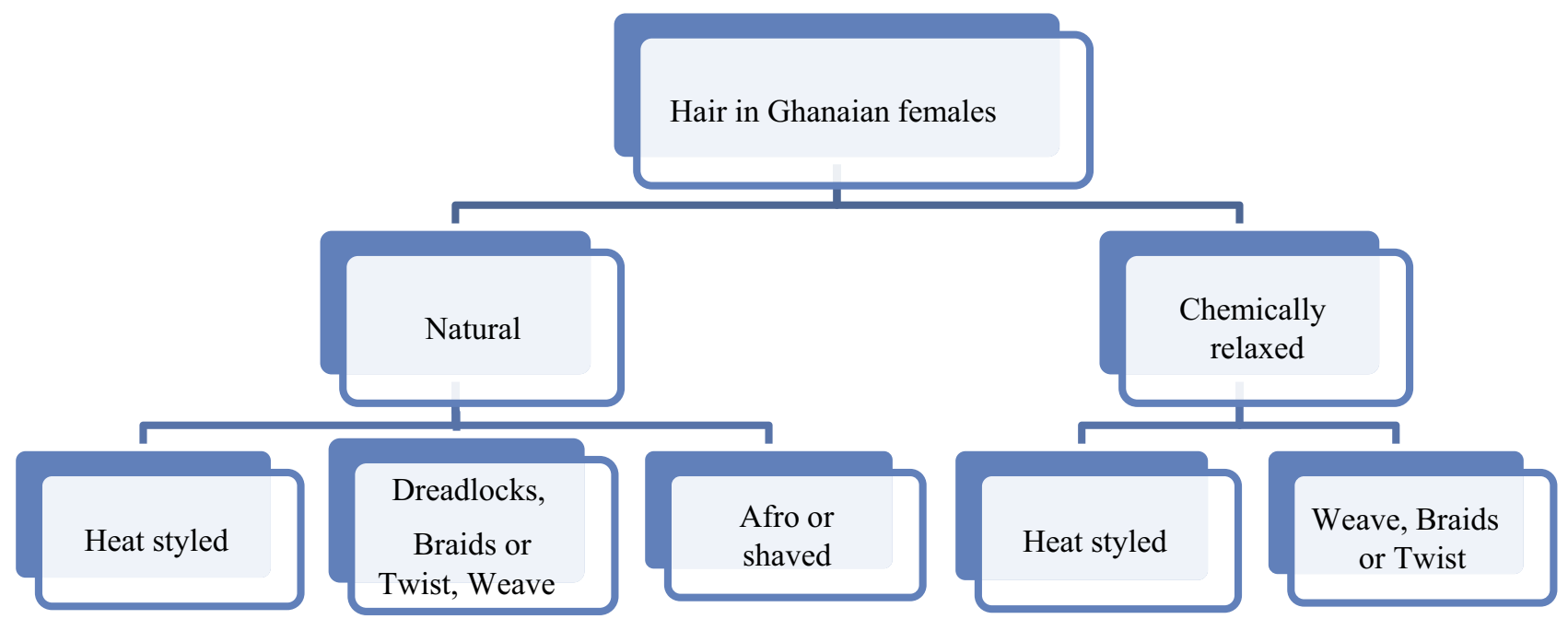

Figure I Line diagram of Negroid African hairstyling techniques and how they overlap. Adapted Roseborough IE, McMichael AJ. Hair care practices in African-American patients. Semin Cutan Med Surg. 2009;28(2):103-108. 
Afro-ethnic hair has been reported to present differences in diameter in many points of the thread when compared with naturally straight hair. ${ }^{11,12}$ Hence, hairs were divided into three sections, proximal $(100 \mu \mathrm{m}$ from the root), distal (100 $\mu \mathrm{m}$ from the tip), and middle (100 $\mu \mathrm{m}$ mid-way of the remaining strand). A thin layer of clear nail polish (Bichun Manicure SuperNail Hardener, Korea) was brushed onto a standard microscope glass slide (Surgifriend Medicals, Middlesex, England). The thin film of nail polish was left untouched for a few minutes to partially solidify, and a strand of hair was placed onto it for adhesion. The nail polish was left to completely dry so that when the hair strand was removed it left a cast of its scales on the adhesive surface of this dried nail polish. To obtain a good scale cast, a cosmetologist's pair of tweezers was used to carefully lift the hair from the dried nail polish on the microscope slide in one smooth motion. The scale casts of the proximal and distal regions of the hair were studied with the same microscope at $40 \times$ objective lens, and digital images were captured. Scales were described and classified according to the patterns, structure of the margins, and distance between scales as previously described by Backwell et $\mathrm{al}^{13}$ and Aboagye. ${ }^{9}$

However, before the hair strand was removed, its dimensional features were determined from proximal to distal with a $10 \times$ objective lens of an optical light microscope (Leica Galen III, Cat No. 317506, Serial No. ZG6JA4). Hair strand characteristics measured included shaft and medullary diameters. Afro-ethnic hairs being ellipsoidal in cross section have major and minor diameters. ${ }^{11}$ These diametric variations were not resolvable at the light microscopic magnification employed in this work.

One eyepiece lens of the microscope was replaced with a digital microscope eyepiece (Lenovo Q350 USB PC Camera) which was connected to a computer (HP Compaq dx2300 Microtower), and digital images were captured and saved using the software CyberLink YouCam (2.0.0.2519, serial no. YUC090105-01, Cyberlink Corporation). A microscope stage graticule $(100 \times 0.01 \mathrm{~mm}$; Graticules Ltd., Tonbridge, UK $)$ was image captured at the same magnification to obtain a standard for calibrating the dimensional measurements.

Digitalized images of hair strands and their scale casts were imported into Microsoft publisher (2009 software) and the software's ruler was calibrated using the image of the microscope stage graticule. All measurements in the publisher units were converted to micrometers as previously described..$^{9,11}$

\section{Data Analyses}

Data obtained were analyzed using Minitab Statistical Software (version 15). All parametric data (age, shaft diameter, medullary diameter, and medullary index) recorded as mean and SD were subjected to one-way ANOVA and the independent $t$-test to determine differences within and between groups. Nonparametric data (scale patterns, scale margins, and presence/type of medulla) were presented as proportions. The test for association was performed using Pearson's correlation. The statistical differences between groups were determined at a 95\% CI. All differences with probability $(p)$ value less than 0.05 were considered significant.

\section{Results}

\section{Age Distribution Of Participants}

The mean age in years for women who had Afro hair was 15.34 (SD 0.87); natural-styled hair was 24.58 (SD 6.88), and chemically relaxed hair was 26.03 (SD 5.08). One-way ANOVA showed a $p$-value of $0.001\left(F\right.$-value $\left.=43.69, R^{2}=0.484\right)$. Newman-Keuls' multiple comparison test showed a significant difference between mean ages of women with Afro hair and natural-styled hair $(\mathrm{p}<0.001)$, as well as between women with Afro hair and chemically relaxed hair $(\mathrm{p}<0.001)$. However, the difference in the mean age of women with natural-styled and chemically relaxed hairs was not significant $(p>0.05)$.

\section{Hair Shaft And Medullary Diameters}

Hair shaft and medullary diameters of proximal and distal parts of hair strands did not show significant differences within the groups; therefore, intergroup comparisons were confined to dimensions of the middle part of the hair shaft. Chemically relaxed hairs had the widest mean shaft diameter whereas the Afro and natural-styled hairs were relatively narrower as shown in Figure 2A and Table 1. Hairs from the vertex of all styling groups had significantly higher shaft diameters compared to other regions. Within the styling groups, the diameters of hair strands from frontal, left temporal, right temporal, and occipital regions were not statistically different.

The mean medullary diameters and indices for hairs from the five scalp regions and the three hairstyle groups are shown in Table 2. The mean medullary diameters ranged between 15 and $20 \mu \mathrm{m}(\mathrm{SD}=4.0-6.5)$ across all scalp regions for the Afro and natural-styled hair groups. As shown in Table 2, medullary diameters from all the scalp regions showed a decreasing trend from Afro, natural-styled to chemically relaxed hair. Medullary diameter for chemically relaxed hair from the left 
A

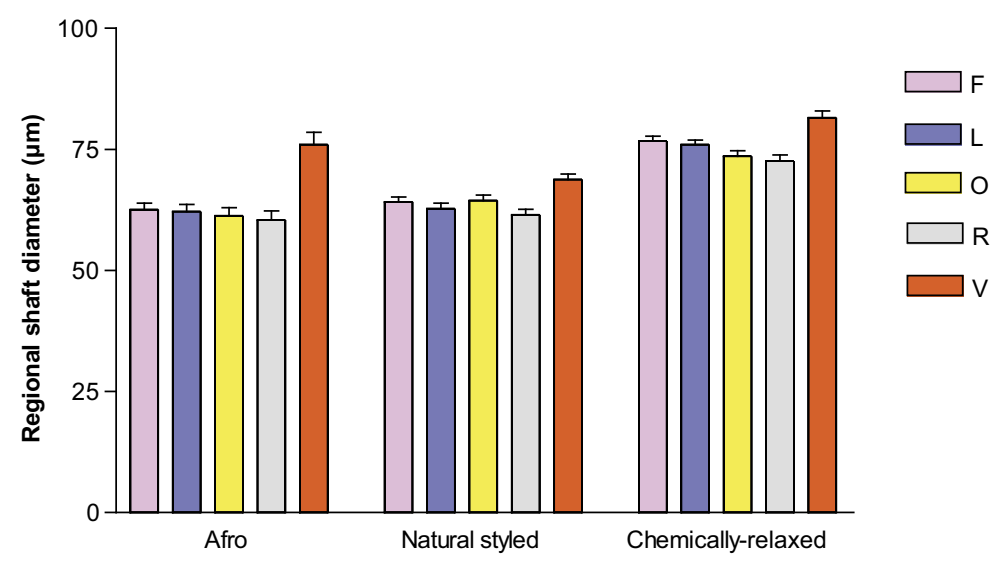

B
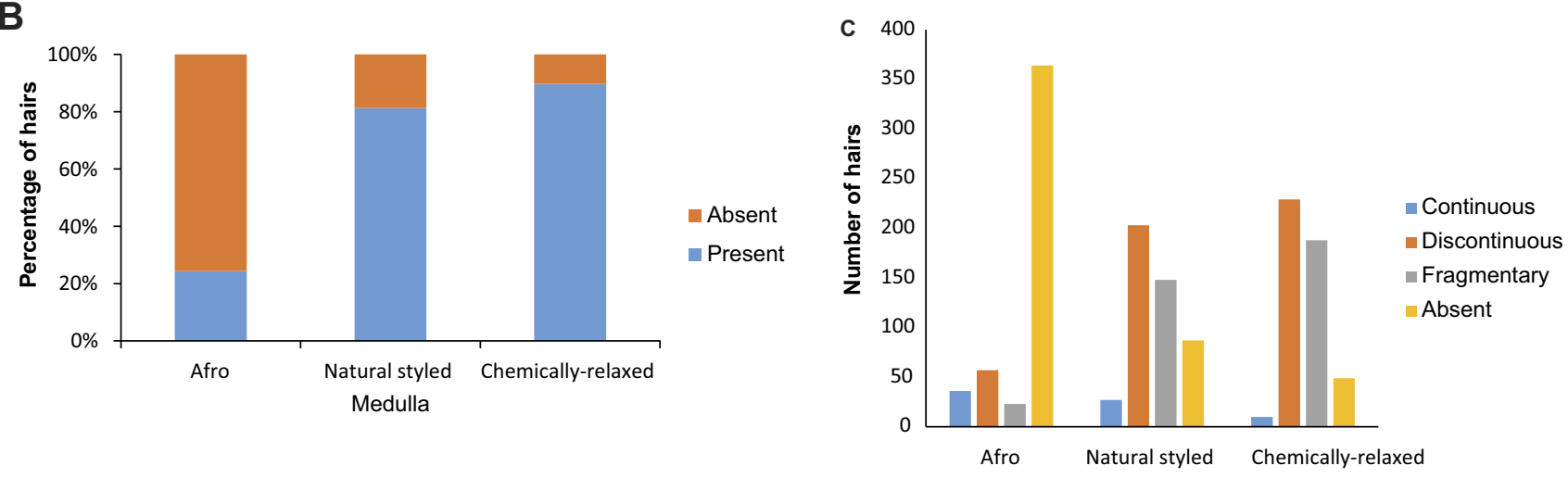

Figure 2 (A-C): Bar charts showing shaft and medulla features of hair strands from women with the three different styling methods. (A) shows hair shaft diameter. Error bars represent SD. (B) shows proportions of hair strands in which the medulla was present or absent. (C) shows proportions of medullary types in the hair strands. Abbreviations: Scalp hair origin; F, frontal; L, left temporal; R, right temporal; O, occipital; V, vertex.

temporal scalp region showed the narrowest medullary diameter $(9.91 \mu \mathrm{m} ; \mathrm{SD}=4.08)$.

The trend of medullary index was highest in the Afro hair, followed by natural-styled hair and then chemically relaxed hair, although the differences were not statistically significant. Graphical representation of hair shaft diameters and the distribution of medulla among various hair-styled groups is shown in Figure $2 \mathrm{~B}$ and $\mathrm{C}$. Chemically relaxed and natural-styled hairs had higher proportions of hairs with observable medulla than the
Afro hair group as shown in Figure 2B. The hair medulla was either "continuous", "discontinuous", or "fragmentary". When hairs from all scalp regions were pooled together, the continuous type of medulla was the least common in this study (Figure 2C). Micrographs showing different appearances of the shaft and medulla within hair strands from participants with the three grooming styles are shown in Figure $3 \mathrm{~A}-\mathrm{C}$.

A significantly positive but modest Pearson's correlation was obtained between medullary and shaft diameters in Afro

Table I Statistical Distribution Of Hair Shaft Diameters From Three Styling Groups, And Among The Five Scalp Areas

\begin{tabular}{|c|c|c|c|c|c|c|}
\hline \multirow[t]{2}{*}{ Scalp Region } & \multicolumn{2}{|l|}{ Afro } & \multicolumn{2}{|l|}{ Natural-Styled } & \multicolumn{2}{|l|}{ Chemically Relaxed } \\
\hline & Mean Diameter $(\mu \mathrm{m})$ & SD & Mean Diameter $(\mu \mathrm{m})$ & SD & Mean Diameter $(\mu \mathrm{m})$ & SD \\
\hline $\mathbf{F}$ & 62.55 & 16.83 & 64.16 & 12.83 & $76.69 *$ & 12.76 \\
\hline $\mathbf{L}$ & 62.17 & 18.57 & 62.74 & 14.59 & $75.99 *$ & 11.78 \\
\hline $\mathbf{R}$ & 60.39 & 23.81 & 61.49 & 14.05 & $72.6 I^{*}$ & $|5.5|$ \\
\hline $\mathbf{0}$ & 61.27 & 21.78 & 64.41 & 14.23 & $73.56^{*}$ & 14.38 \\
\hline $\mathbf{V}$ & 76. $01 * *$ & 31.9 & $68.75^{* *}$ & 14.93 & $81.54 * * * *$ & 17.61 \\
\hline
\end{tabular}

Notes: *Significance $(p<0.05)$ of comparison between Afro and chemically relaxed hair. Significance $(p<0.05)$ of comparison between Afro, natural-styled, and chemically relaxed hair. Abbreviations: Scalp hair origin; F, frontal; L, left temporal; R, right temporal; O, occipital; V, vertex. 
Table 2 Medullary Diameters And Indices For Each Hairstyle From The Five Scalp Regions

\begin{tabular}{|l|l|l|l|l|l|l|l|l|l|}
\hline \multirow{2}{*}{ Scalp Regions } & \multicolumn{2}{l}{ Afro } & \multicolumn{2}{l|}{ Natural-Styled } & \multicolumn{2}{l|}{ Chemically Relaxed } \\
\cline { 2 - 10 } & N & Diameter (SD) & Index (SD) & N & Diameter (SD) & Index (SD) & N & Diameter (SD) & Index (SD) \\
\hline F & 7 & $19.50(3.59)$ & $0.260(0.057)$ & 24 & $14.95(4.75)$ & $0.224(0.067)$ & 17 & $16.99(11.53)$ & $0.206(0.129)$ \\
$\mathbf{L}$ & 17 & $19.08(6.32)$ & $0.273(0.103)$ & 16 & $14.85(4.92)$ & $0.236(0.113)$ & 18 & $9.916(4.08)$ & $0.128(0.062)$ \\
R & 16 & $16.99(4.06)$ & $0.237(0.039)$ & 18 & $14.71(4.39)$ & $0.213(0.060)$ & 17 & $14.27(9.56)$ & $0.169(0.105)$ \\
$\mathbf{O}$ & 15 & $15.48(4.01)$ & $0.229(0.078)$ & 19 & $14.32(6.20)$ & $0.210(0.084)$ & 21 & $13.02(5.89)$ & $0.171(0.084)$ \\
V & 8 & $15.47(4.19)$ & $0.187(0.047)$ & 17 & $15.23(4.59)$ & $0.197(0.052)$ & 20 & $14.94(8.78)$ & $0.178(0.110)$ \\
\hline
\end{tabular}

Abbreviations: Scalp hair origin; F, frontal; L, left temporal; R, right temporal; O, occipital; V, vertex; N, number of hair strands.

hairs $(\mathrm{r}=0.320 ; \mathrm{p}=0.011)$ and natural-styled hairs $(\mathrm{r}=0.235$; $\mathrm{p}=0.022)$, but not in chemically relaxed $(\mathrm{r}=1.22 ; \mathrm{p}=0.20)$.

\section{Hair Scale Patterns}

The distribution of scale patterns is described and shown in Figure 4. Samples of micrographs of scale patterns found in hairs studied are presented in Figure 5. Hair scales were categorized based on the structure of their margins (smooth, rippled, and crenate) and the distance between scale margins (as close, near, and distant). The scales were also classified by the patterns formed along the hair shaft circumference (as regular/irregular waves, or mosaic).

The regular mosaic scale pattern had the least occurrence in hairs among all the three studied grooming styles, followed by the regular and irregular wave patterns, with the irregular mosaic pattern having the largest representation (Figure 4A). Scale margins showed Afro hairs having the largest proportion of smooth scale margin, with natural-styled and chemically relaxed hairs combined representing only about one-third of the entire smooth scale pattern (Figure 4B). About half the hair strands with crenate scale margin were Afro, with the remaining half being shared between natural-styled and chemically relaxed hairs, of which the chemically relaxed hairs had the least number of crenate scale margins. The occurrence of rippled scale margins was highest among natural-styled hairs with about half the total, while the other half was evenly distributed between the Afro and chemically relaxed groups (Figure 4B).

\section{Discussion}

The uniqueness of African-ethnic or Negroid hair has been emphasized by some researchers. ${ }^{3,14-16}$ It is however still asserted that information is relatively sparse on Negroid hair $^{15}$ despite being a huge potential market for hair products. This is more so because sociocultural pressures cause Negroid females to adopt grooming procedures that mainly straighten their hair and oppose their natural hair conditions. ${ }^{3}$

This present study is probably the first that reports structural changes of hair that result from common grooming styles of indigenous Ghanaian women and contributes to researched information on Afro-textured hair. ${ }^{11,14-16}$
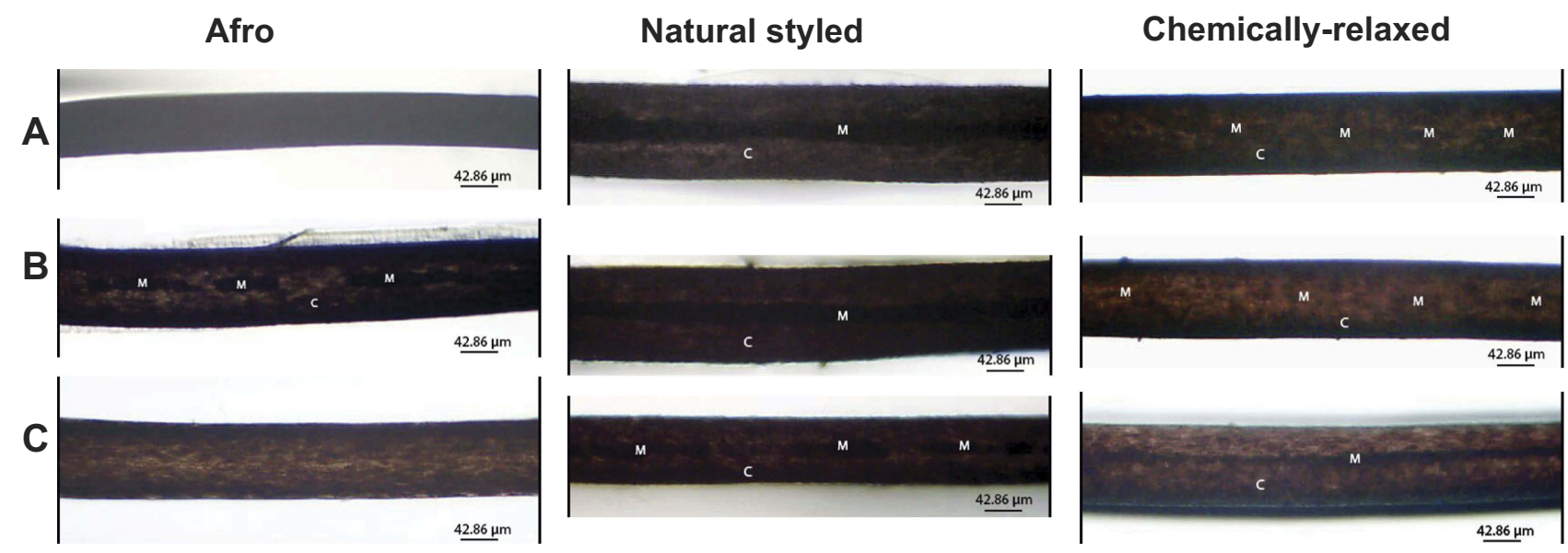

Figure 3 (A-C): Micrographs showing the cortex and medulla of hair from different parts of hair strands from various hairstyle groups. (A) shows the cortex (C) and medulla (M) of proximal hair, whereas (B) and (C) show strands from middle and distal parts, respectively. 
A

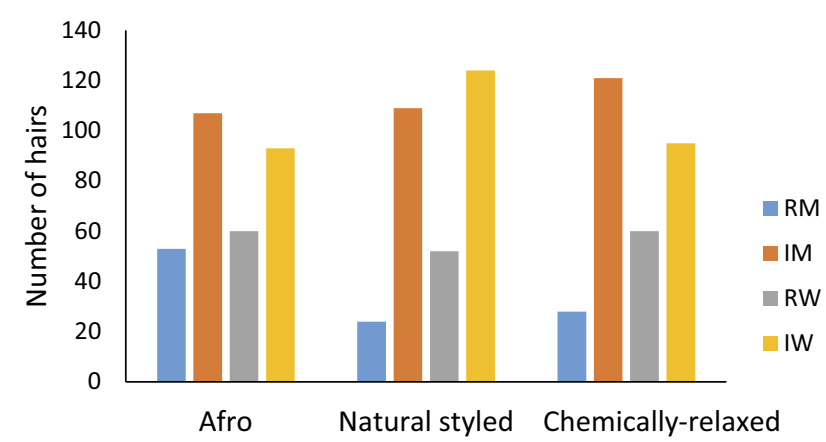

Scale pattern
B

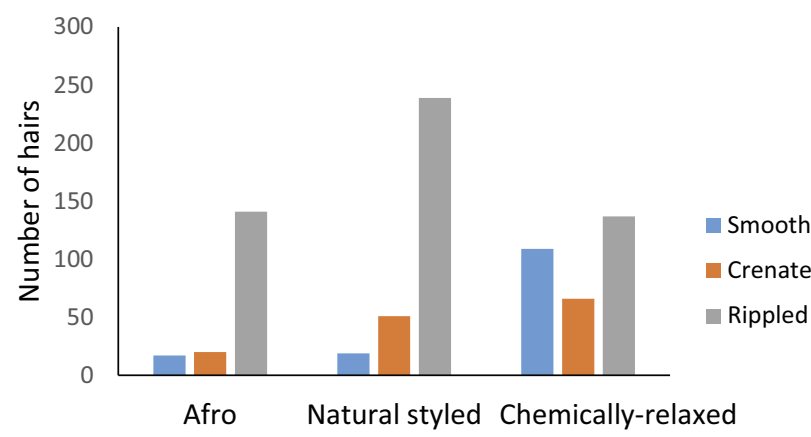

Scale margins

Figure 4 (A, B): Bar charts showing occurrence of conventional descriptive scale features among hair fibers from women with the three grooming styles studied. (A) shows the number of hair fibers that showed conventional scale patterns. B shows the number of hairs that had the cuticular scale margins conventionally described as crenate, smooth, and rippled.

Abbreviations: RM, regular mosaic pattern; IM, irregular mosaic pattern; RW, regular wave pattern; IW, irregular wave pattern.

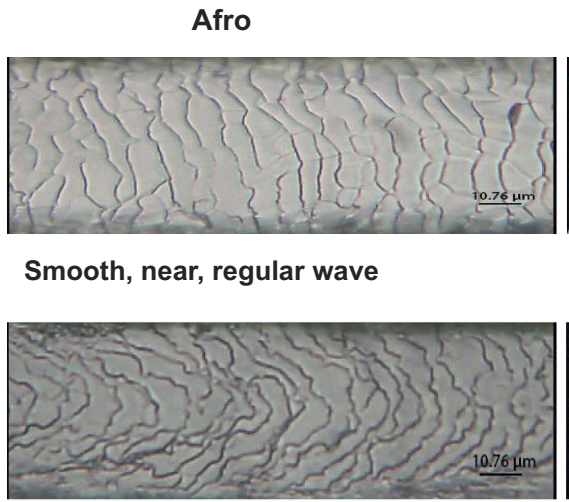

Rippled,close, irregular wave

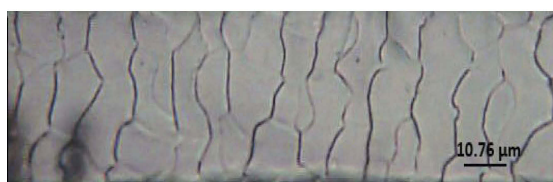

Smooth, distant, regular mosaic
Natural styled

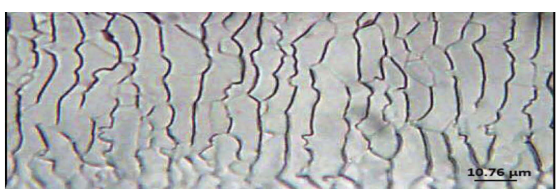

Crenate, distant, irregular mosaic

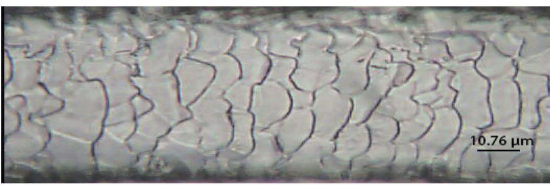

Smooth, distant, irregular mosaic

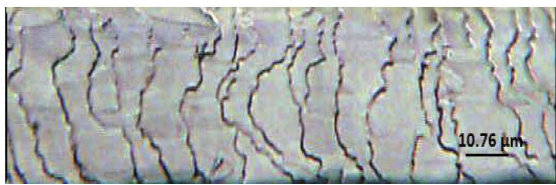

Crenate, near, regular wave
Chemically-relaxed

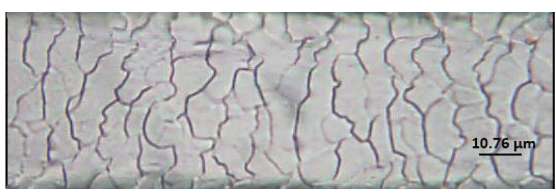

Crenate, distant, regular mosaic

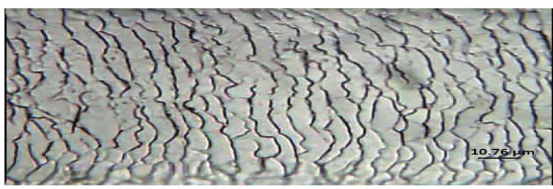

Crenate, close, regular wave

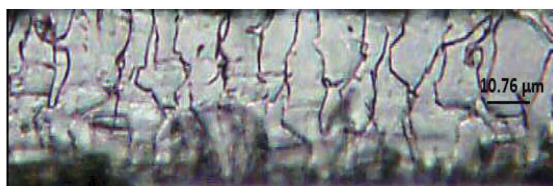

Ripple, distant, irregular mosaic

Figure 5 Micrographs showing samples of conventional descriptive patterns and margin morphologies of cuticular scales found among the three grooming styles studied. Scale casts were prepared, and images digitally captured as described in the 'Materials and Methods' section; tone, contrast, and color of images were enhanced to make scales more visible.

The hair-grooming styles in this study were natural unstyled (Afro or virgin), natural styled (braids, twists, corn-row, or weaved), and relaxed styled, which have been excellently reviewed. ${ }^{15}$ It has been observed that cosmetic hair care procedures are mostly used by African-descendent women, whose hair fragility has been reported to worsen by hair care practices. ${ }^{16}$ However, we agree with Aryiku et $\mathrm{al}^{16}$ that women with Afro-textured hair are motivated to adopt hair-straightening grooming for reasons including easier manageability of hair, perceived beauty, improved self-esteem, and social acceptance.

In Ghana, grooming of female hair commences early because it is a cultural norm to braid and weave the hair of baby girls. Indeed, it is only during school term that some authorities prohibit hair grooming other than trimming. Thus, in Ghana, unstyled (Afro) Negroid hair is commoner among teenagers in preuniversity school, hence the lower mean age of females with natural unstyled (Afro) hair in 
this study. Adult females adopt hair-grooming styling and hence the comparable mean age of participants in this study who had natural styled (cornrow or braided) or relaxed (chemically) styled hair. It is germane to this point that Quaresma et al $^{14}$ cite literature that indicates that approximately $80 \%$ of African descent women use chemicals to relax their hair.

Noteworthily, there were no scalp-regional differences in hair scale characteristics in this study. This suggests that alteration of hair scale characteristics did not vary depending on whether it was located at the frontal, vertex, left or right parietal, or occipital region of the skull. This contrasts with findings by Loussouarn ${ }^{17}$ that the total hair density, as well as ratio of telophase hairs to total hairs (T\%) in three scalp areas (vertex, temple, and occiput) significantly varied in both men and women. These authors however did not compare the dimensional data of their hairs according to scalp area.

The diameter of hair shaft was smallest while the medullary diameter was widest in Afro (natural unstyled hair). These dimensions were intermediate for naturalstyled hair, while relaxed (chemically) styled hair had the largest shaft and least medulla. It is inferred that styling was accompanied by increased shaft diameter but reduction in medulla width. This interpretation was affirmed by the trend of medullary index which was least in Afro (natural-unstyled) hair, intermediate for natural-styled hair, and largest for relaxed styled hair. Support for the deduction that hair relaxing increases shaft size is found in the report that the high $\mathrm{pH}$ of chemicals used to relax Afro-textured hair results in swelling of the shaft by opening the cuticle and exposing the cortex and keratin. ${ }^{12,16}$ Tanus et $\mathrm{al}^{15}$ asserted that ammonium thioglycolate is an alkaline agent that promotes swelling of the hair cuticle in blackwoman's hair making it capable of penetrating into the hair cortex and promoting the rearrangement of disulfide bridges so that the hair can be shaped according to her wishes. Furthermore, Miranda-Vilela et al $^{7}$ posited that one of the damages that occur by applying chemical straighteners to hair is the removal of the monomolecular layer of fatty acids covalently bound to the cuticle, including 18-methyl eicosanoic acid. This hydrophobic layer retards water from wetting and penetrating the hair shaft and changing its physical properties. Removal of the fatty acid layer decreases the brightness of the hair, making it more susceptible to static electricity and frizzing induced by humidity. In other, words relaxing chemicals make hair penetrable by water, ${ }^{11,12,18}$ which may account for the shaft swelling earlier mentioned.

Generally, hair shaft and medullary diameters are positively correlated. ${ }^{7,9,13}$ The finding in the present study that natural hairs exhibited this phenomenon, but relaxed hairs did not, is therefore interesting. The possible explanation emanates from the observations made earlier concerning the changes in shaft size after treatment with relaxing chemicals. These structural changes associated with chemically relaxed hair possibly included reducing their melanin (pigment) content, hence making the medulla more visible than it is in Afro or natural-styled hair. This could account for the higher proportion of chemically relaxed hairs in which medulla was present compared with hairs in the other styling groups. It is also suggested from this study that whenever big medullary indices (larger shaft diameters and smaller medulla diameters) are obtained from Ghanaian/African hair samples, the possibility that the hairs have been chemically relaxed ought to be considered. It is attractive to propose that damage will be minimized when chemicals for treating Afro hair are made less able to render the shaft moisture penetrable.

In forensic identification, the findings from this study provide a guide for identifying Ghanaian women from hair samples. In the global use of hair in forensics, our findings suggest consideration of structural modifications due to styling of African hair. It may therefore be necessary to add treated African hair samples to databases on hair.

\section{Conclusion}

It is concluded that compared to Afro (natural unstyled) scalp hair, nonchemical styling of ethnic African scalp hair of Ghanaian females did not significantly alter the hair features but styling by application of chemicals did. Chemically styled hair had greater shaft diameter suggesting they became more penetrable to water by removal of waterproofing components causing them to swell. Effort to minimize the water-penetrable impact of chemicals used for treating Afro hair may preserve its natural structure and reduce structural damage.

\section{Acknowledgment}

We acknowledge the College of Health Sciences, University of Ghana, for providing financial support for this study.

\section{Disclosure}

The authors report no conflicts of interest in this work. 


\section{References}

1. Khumalo NP, Doe PT, Dawber RP, Ferguson DJP. What is normal black African hair? A light and scanning electron-microscopic study. $J$ Am Acad Dermatol. 2000;43:814-820. doi:10.1067/mjd.2000.107958

2. Lewallen R, Francis S, Fisher B, et al. Hair care practices and structural evaluation of scalp and hair shaft parameters in African American and Caucasian women. J Cosmet Dermatol. 2015;14(3):216-223. doi:10.1111/jocd.12157

3. Cruz C, Costa C, Gomes A, Matamá T, Cavaco-Paulo A. Human hair and the impact of cosmetic procedures: a review on cleansing and shape-modulating cosmetics. Cosmet. 2016;3(3):26. doi:10.3390/ cosmetics 3030026

4. Hinsz VB, Matz DC, Patience RA. Does women's hair signal reproductive potential? J Exp Soc Psychol. 2001;37(2):166-172. doi:10.1006/jesp.2000.1450

5. Johnson T, Bankhead T. Hair it is: examining the experiences of black women with natural hair. Op J Soc Sci. 2014;2:86-100.

6. Roseborough IE, McMichael AJ. Hair care practices in AfricanAmerican patients. Semin Cutan Med Surg. 2009;28(2):103-108. doi:10.1016/j.sder.2009.04.007

7. Miranda-Vilela AL, AdJ B, Muehlmann AL. An overview of chemical straightening of human hair: technical aspects, potential risks to hair fibre and health and legal issues. Int J Cosmet Sci. 2013;36(1):2-11. doi: $10.1111 /$ ics. 12093

8. Nissimov JN, Das Chaudhuri AB. Hair curvature: a natural dialectic and review. Biol Rev Camb Philos Soc. 2014;89(3):723-766.

9. Aboagye B. Comparative characteristics of black and grey chest and selected facial hairs in Negroid males. Inte J Biol Anthrop. 2014;7 (1): $1-9$.
10. Kalmoni Y, Addai FK, Adjenti SK, et al. Light microscopic morphology of indigenous Ghanaian African hair from scalp, eyebrow, axilla, and pubic regions. Int J Trichology. 2019;11(1):8-13. doi:10.4103/ijt. ijt_70_18

11. Franbourg A, Hallegot P, Baltenneck F, Toutain C, Leroy F. Current research on ethnic hair. J Am Acad Dermatol. 2003;48(6 Suppl): S115-S119. doi:10.1067/mjd.2003.277

12. De Sá Dias TC, Baby AR, Kaneko TM, Robles Velasco MV. Relaxing/straightening of Afro-ethnic hair: historical overview. $J$ Cosmet Dermatol. 2007;6(1):2-5. doi:10.1111/jcd.2007.6.issue-1

13. Backwell L, Pickering R, Brothwell D, et al. Probable human hair found in a fossil hyaena coprolite from Gladysvale cave, South Africa. J Archaeol Sci. 2009;36(6):1269-1276. doi:10.1016/j. jas.2009.01.023

14. Quaresma MV, Martinez Velasco MA, Tosti A. Hair breakage in patients of African descent: role of dermoscopy. Skin Appendage Disord. 2015;1(2):99-104. doi:10.1159/000436981

15. Tanus A, Oliveira CCC, Villarreal DJV, Sanchez FAV, Dias MFRG. Black women's hair: the main scalp dermatoses and aesthetic practices in women of African ethnicity. An Bras Dermatol. 2015;90 (4):450-465. doi:10.1590/abd1806-4841.20152845

16. Aryiku SA, Salam A, Dadzie OE, Jablonski NG. Clinical and anthropological perspectives on chemical relaxing of afro-textured hair. $J$ Eur Acad Dermatol Venereol. 2015;29(9):1689-1695.

17. Loussouarn G. African hair growth parameters. $\mathrm{Br} J$ Dermatol. 2001;145(2):294-297. doi:10.1046/j.1365-2133.2001.04350.x

18. Khumalo NP, Dawber RPR, Ferguson DJP. Apparent fragility of African hair is unrelated to the cystine-rich protein distribution: a cytochemical electron microscopic study. Exp Dermatol. 2005;14 (4):311-314. doi:10.1111/exd.2005.14.issue-4

\section{Publish your work in this journal}

Clinical, Cosmetic and Investigational Dermatology is an international, peer-reviewed, open access, online journal that focuses on the latest clinical and experimental research in all aspects of skin disease and cosmetic interventions. This journal is indexed on CAS.
The manuscript management system is completely online and includes a very quick and fair peer-review system, which is all easy to use. Visit http://www.dovepress.com/testimonials.php to read real quotes from published authors. 